\title{
The role of vertebral angiography in the investigation of third nerve palsy
}

\author{
MP BARNES, BJ HUNT, IR WILLIAMS \\ From the Mersey Regional Department of Medical and Surgical Neurology, Walton Hospital, Liverpool, UK
}

SUMMARY The association between intracranial aneurysm and third nerve palsy in a series of fifty patients presenting to this unit over a six year period has been studied. All aneurysms causing a third nerve palsy were found to be in the anterior circulation and all were adequately demonstrated by carotid angiography alone. None of the thirty cases of posterior circulation aneurysm was associated with a third nerve palsy. Vertebral angiography carries a higher risk of serious complication than carotid angiography. We feel that the added risk of vertebral angiography is not justified for the investigation of an isolated third nerve palsy.

Isolated paralysis of the third cranial nerve can be caused by neoplasm, aneurysm, head trauma, vascular or inflammatory disease. ${ }^{1}$ If the cause is not found by means of non-invasive investigations, such as skull radiography or CT scan, then it is usual to proceed to angiography with a view to demonstrating either granulomatous disease, such as the Tolosa-Hunt syndrome, or an intracranial aneurysm.

The most common site of an aneurysm causing a third nerve palsy is the junction of the internal carotid and posterior communicating arteries (PCoA aneurysm). ${ }^{2}$ Aneurysms at other sites on the internal carotid artery or in the basilar-posterior cerebral territory can also produce a third nerve palsy. ${ }^{2-4}$ Most of these aneurysms will be shown by carotid angiography. If no aneurysm is seen on carotid studies then vertebral angiography may be performed to demonstrate either a PCoA aneurysm filling from the posterior circulation or an aneurysm of the vertebrobasilar system. However, vertebral angiography is associated with a higher risk of morbidity and mortality than carotid studies. ${ }^{56}$ In addition, surgery for posterior circulation aneurysms carries a higher risk in the age group in which they are most frequently found. Therefore,

Address for reprint requests: Dr MP Barnes, Mersey Regional Department of Medical and Surgical Neurology, Walton Hospital, Rice Lane, Liverpool L9 1AE, UK.

Received 30 July 1981

Accepted 29 August 1981 we have investigated the circumstances in which vertebral angiography is justified for the investigation of a third nerve palsy.

\section{Patients and methods}

We have reviewed three groups of patients, all of whom were admitted to the Mersey Regional Department of Medical and Surgical Neurology during the six year period 1973-1978, during which 510 patients were admitted with intracranial aneurysm: Group 1 - 50 patients with an intracranial aneurysm associated with a third nerve palsy, in order to assess the relative frequency of occurrence in the anterior compared to the posterior circulations; Group 2-132 patients with a PCoA aneurysm, with or without a third nerve palsy, in order to assess whether such aneurysms are adequately demonstrated by carotid angiography alone; Group $3-30$ patients with an aneurysm of the posterior circulation, in order to assess the association between these aneurysms and a third nerve palsy.

\section{Results}

\section{GROUP 1}

Fifty patients had a third nerve palsy associated with an intracranial aneurysm (table 1). No aneurysm of the vertebrobrasilar system produced an oculomotor palsy. All aneurysms were demonstrated by carotid angiography alone. Twenty-one patients presented with an isolated oculomotor palsy, 29 presented with a subarachnoid haemorrhage associated with the third nerve palsy. 
Table 1 Aneurysms associated with a third nerve palsy

\begin{tabular}{|c|c|c|}
\hline Site & Total & $\begin{array}{l}\text { Demonstrated by carotid } \\
\text { angiography alone }\end{array}$ \\
\hline \multicolumn{3}{|l|}{$\begin{array}{l}\text { Carotid } \\
\quad \text {-Supraclinoid }\end{array}$} \\
\hline$-\mathrm{PCoA}$ & 43 & 43 \\
\hline $\begin{array}{c}\text {-Internal carotid } \\
\text { bifurcation }\end{array}$ & 3 & 3 \\
\hline -Ophthalmic & $1^{*}$ & 1 \\
\hline _Infraclinoid & $3 \dagger$ & 3 \\
\hline Vertebrobasilar & 0 & 0 \\
\hline & $\overline{50}$ & $\overline{50}$ \\
\hline
\end{tabular}

*Associated with a palsy of the fourth and sixth nerves and proptosis. $\dagger$ Two of these were associated in addition with palsies of the fourth. fifth (upper division) and sixth nerves

GROUP 2

One hundred and thirty-two patients were found to have a PCoA aneurysm, 12 medical records were untraceable. Table 2 shows the presenting features of the remaining 120 patients. Forty-three patients $(36 \%)$ had a third nerve palsy, 25 of whom had an associated subarachnoid haemorrhage. One aneurysm was found incidentally during angiography for suspected sub-dural haematoma. All PCoA aneurysms were demonstrated by carotid angiography alone. Vertebral studies were performed in 14 cases but did not yield any further useful information. It is of interest that there was a female:male ratio of approximately $4: 1$ in those who presented with a subarachnoid haemorrhage but the ratio was approximately $1: 1$ in those who presented with a third nerve palsy alone.

Table 2 Presentation of PCoA aneurysms

Subarachnoid Subarachnoid Third nerve Incidental Total

haemorrhage haemorrhage palsy alone finding

alone plus third

nerve palsy

\begin{tabular}{lccccc}
\hline Male & $15^{*}$ & 4 & 8 & 0 & 27 \\
Female & $61 \dagger$ & $21^{\ddagger}$ & 10 & 1 & 93 \\
Total & $\frac{76}{25}$ & 25 & 18 & -1 & $\frac{1}{120}$ \\
\hline
\end{tabular}

*One had a unilateral hemiparesis; $\uparrow 8$ had a unilateral hemiparesis and one a homonymous hemianopia; $¥ 2$ had a unilateral hemiparesis.

G ROUP 3

Table 3 shows the site of the 30 cases of posterior circulation aneurysm. All cases presented with a subarachnoid haemorrhage and none was associated with a third nerve palsy.

\section{Discussion}

Oculomotor palsy is recognised as an important indicator of an intracranial aneurysm. Rucker, 1 in a large series, found that about $18 \%$ of third
Table 3 Site of posterior circulation aneurysms

\begin{tabular}{lc}
\hline Site & Total \\
\hline Basilar artery (bifurcation) & 17 \\
Posterior inferior cerebellar artery & 8 \\
Posterior cerebral artery & 4 \\
Vertebral artery & 1 \\
& $\overline{30}$
\end{tabular}

nerve palsies were due to aneurysm. The site could be conveniently divided into three groups; infraclinoid and supraclinoid aneurysms of the internal carotid artery or its branches and aneurysms of the vertebrobasilar system. The supraclinoid group is the commonest accounting for $94 \%$ of the aneurysms causing a third nerve palsy in our series, in comparison with $82 \%$ in a series by Cogan. ${ }^{2}$ The aneurysm almost invariably arises at the origin of the posterior communicating artery but can arise at the origin of the anterior cerebral artery, ${ }^{4}$ anterior communicating artery, ${ }^{4}$ ophthalmic artery, ${ }^{2}$ or at the internal carotid bifurcation. In this series $6 \%$ of aneurysms causing a third nerve palsy were in the infraclinoid group, compared to $14 \%$ of Cogan's series. ${ }^{2}$ These aneurysms are usually associated with palsies of the third, fourth, fifth (upper division) and sixth cranial nerves, as in two of our cases.

Aneurysms of the vertebrobasilar system may cause a third nerve palsy, but this is unusual. The most common sites are at the distal end of the basilar artery or the proximal posterior cerebral artery. $^{2} 37$ There were 21 aneurysms at these two sites in our series but none was associated with a third nerve palsy. Sarner and Rose $^{8}$ found that four of 36 cases of vertebrobasilar aneurysm had a third nerve palsy. Cogan ${ }^{2}$ found that only $4 \%$ of aneurysms causing a third nerve palsy were in the vertebrobasilar system. It is, therefore, possible, but unlikely, that an aneurysm causing a third nerve palsy would not be detected on carotid angiography. However, surgery for aneurysms in the posterior circulation is hazardous and, even in specialised centres, is still associated with a high morbidity and mortality. 910 In most centres a conservativeapproach to these aneurysms is still adopted.

Vertebral angiography is associated with a higher risk of serious complication than carotid angiography. In Takahashi's series of 422 angiograms $^{6}$ all neurological complications occurred in vertebral studies. Wishart ${ }^{5}$ found a higher risk of neurological complications $(6.5 \%)$ in vertebral studies compared to carotid injection $(4 \cdot 2 \%)$. Olivecrona ${ }^{11}$ reports a more favourable comparison between vertebral and carotid angiography but his paper does show that despite accounting for only $22 \%$ of angiograms, vertebral studies produced $33 \%$ of the permanent 
neurological sequelae. Mani, ${ }^{12}$ however, found no significant difference in complication rates according to the vessel injected. Despite this recent promising report, if vertebral angiography is shown to be unnecessary for the investigation of a third nerve palsy, this can only be of benefit to the individual patient.

All aneurysms in our series causing a third nerve palsy were in the supraclinoid or infraclinoid groups and all were demonstrated by carotid angiography. Vertebrobasilar aneurysms are relatively infrequent, accounting for only $6 \%$ of our series, and are rarely associated with an oculomotor palsy. In view of the higher mortality and morbidity of surgery for posterior circulation aneurysms the risk of missing a surgically treatable vertebrobasilar aneurysm is very small. We feel that the added risk of vertebral angiography is not justified in the investigation of an isolated third nerve palsy presenting without associated subarachnoid haemorrhage.

We wish to thank the neurologists and neurosurgeons in the Regional Department of Medical and Surgical Neurology for access to their records. Dr NR Clitherow has been of great help in the interpretation of the radiographs.

\section{References}

${ }^{1}$ Rucker CW. The causes of paralysis of the third, fourth and sixth cranial nerves. Am J Ophthalmol
$1966 ; 62: 1293-8$.

${ }^{2}$ Cogan DG, Mount HTJ. Intracranial aneurysms causing ophthalmoplegia. Arch Ophthalmol 1963; 70:757-71.

${ }^{3}$ Trobe JD, Glaser JS, Quencer RC. Isolated oculomotor paralysis The product of saccular and fusiform aneurysms of the basilar artery. Arch Opthalmol 1978;96:1236-40.

${ }^{4}$ Hepler RS, Cantu RC. Aneurysms and third nerve palsies. Arch Ophthalmol 1967;77:601-8.

${ }^{5}$ Wishart DL. Complications in vertebral angiography as compared to non-vertebral cerebral angiography in 447 studies. Am $J$ Roentgenol Radium Ther Nucl Med 1971;113:527-37.

${ }^{6}$ Takahashi M, Kawanami H. Femoral catheter techniques in cerebral angiography - an analysis of 422 examinations. Br J Radiol 1970;43:771-5.

7 Kerns JM, Smith DR, Jannotta FS, Alper MG. Oculomotor nerve regeneration after aneurysm surgery. Am J Ophthalmol 1979;87:225-33.

${ }^{8}$ Sarner M, Rose FC. Clinical presentation of ruptured intracranial aneurysm. J Neurol Neurosurg Psychiatry $1967 ; 30: 67-70$.

${ }^{9}$ Wilson CB, Hoi Sang U. Surgical treatment for aneurysms of the upper basilar artery. $J$ Neurosurg 1976;44:537-43.

${ }^{10}$ Chou SN, Ortiz-Suarex HJ. Surgical treatment of arterial aneurysms of the vertebrobasilar circulation. J Neurosurg 1974;41:671-80.

11 Olivecrona H. Complications of cerebral angiography. Neuroradiology 1977;14:175-81.

12. Mani RL, Eisenberg RL. Complications of catheter cerebral arteriography: analysis of 5000 procedures. III. Assessment of arteries injected, contrast medium used, duration of procedure and age of patient. AJR 1978;131 :871-4. 